MATEC Web of Conferences 22,04011 (2015)

DOI: $10.1051 /$ matecconf/ 20152204011

(C) Owned by the authors, published by EDP Sciences, 2015

\title{
Research on Application of Internet of Things in the Disposal of Envi- ronmental Emergency
}

\author{
Yanju Zhu \\ Hohai University, Nanjing, Jiangsu, China \\ Taishan Medical College, Tai'an, Shandong, China
}

\begin{abstract}
Internet of things is an important part of a new generation of information technology and also an important stage of Information Age. Application of Internet of things in the disposal of environmental emergency is an inevitable trend of application of Internet of things in the field of environmental protection. This paper summarizes the principle, process and application field of Internet of things, and focuses on the general framework of environmental emergency disposal system based on Internet of things and further analyses the factors of restricting application of Internet of things in the disposal of environmental emergency. At last, the suggestions and countermeasures to optimize environmental emergency disposal system are proposed.
\end{abstract}

Keywords: internet of things; application; disposal of environmental emergency

\section{INTRODUCTION}

With the rapid development of economy, increasing growth of population and concentration of industrial enterprises, the amounts of Chinese environmental emergency have increased year by year. As shown in Figure 1, from 2009 to 2013, the numbers of environmental emergency are $418,420,542,542$, and 712 respectively. In 2013, the speed of increasing is the largest, reaching $31 \%{ }^{[1]}$. These accidents have the characteristics of a variety of forms, suddenness of happening, difficulties of processing, and serious harm to the environment. These make the managers difficult to deal with timely and effectively, bring the people great panic and even affect the safety of the personal. These also bring the unstable factors in the society. Therefore, we try to prevent environmental emergency, monitor the emergency rapidly and dispose the emergency rapidly, accurately and effectively to minimize the harm of environmental emergency.

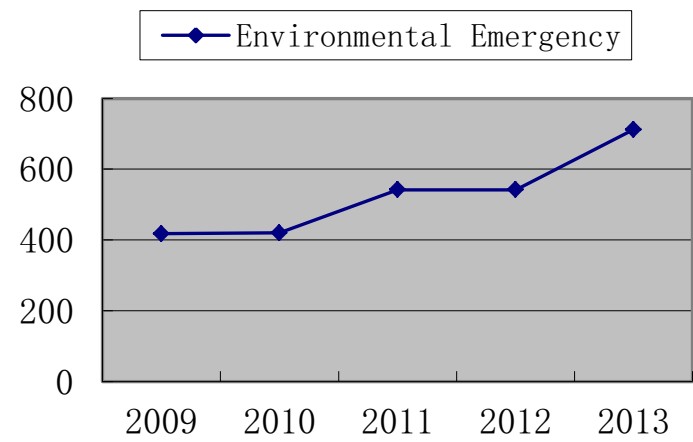

Figure 1. Diagram of the number of China environmental emergency in 2009-2013
Application of Internet of things in the disposal of environmental emergency is that the sensors and a variety of environmental monitoring equipment are embedded in the monitoring objects with the help of Internet of things, and then the monitoring objects are integrated through the Internet and cloud computing to realize the monitoring \& management of environmental emergency. Application of Internet of things in the disposal of environmental emergency is the inevitable result of the development of information \& communication technology, the inevitable trend of development of information technology in the field of environmental protection and also an important measure to speed up the historic transformation of environmental protection.

\section{SUMMERY OF INTERNET OF THINGS}

What is Internet of things? Internet of things is the vast distributed network that gives the objects smart, connects the objects to the Internet through the interface and forms the connection between goods and goods through the radio frequency identification system (RFID), infrared sensing system, global position system (GPS), laser scanners and other information sensing equipment. This can realize intelligent identification, positioning, tracking, supervision and management of items ${ }^{[2]}$. From this definition, we can see that the essence of Internet of things is the extension of application and the basis \& core of network of Internet of things is still the Internet.

As shown in Figure 2, the process of Internet of things principle is to use the sensor and modern data acquisition equipment pre-embedded in the goods or equipment to make the information of items in the 


\section{MATEC Web of Conferences}

physical world be data-driven at utmost, use item identification technology and communication technology to make the data information of items link into the Internet, deliver these messages to the server to collation, processing, analysis and visualization, use the results of the analysis and processing to manage and control the personnel, machines, equipment and infrastructure within the network.

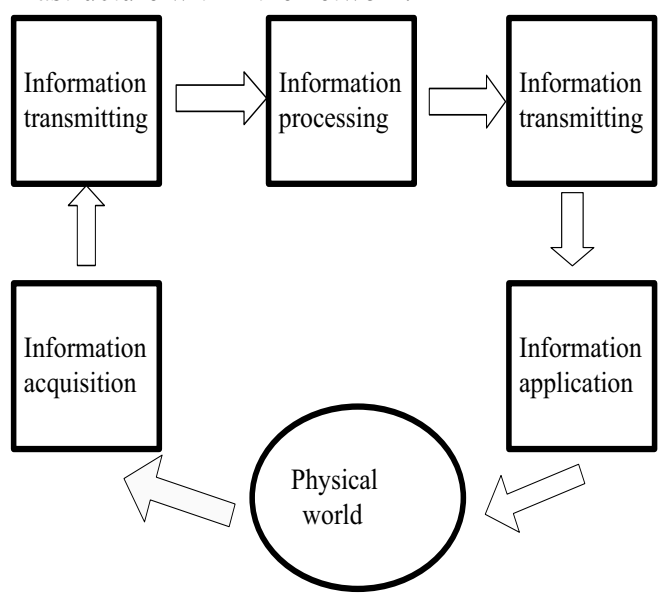

Figure 2. Diagram of the principle of the Internet of things

Internet of things is widely used in many fields, such as intelligent grid, intelligent transportation, in telligent medical care, intelligent finance, intelligent home furnishing, intelligent agriculture and intelligent national defense. The main role is to reduce the distance between the physical world and the information system, realize the integration of human society and the physical world to control and manage the physical world in real-time. This makes human manage the production and life more sophisticatedly to achieve the state of "Wisdom". It can improve the utilization rate of resources and improve the relationship between human and nature.

3 GENERAL FRAMEWORK OF THE DISPOSAL SYSTEM OF ENVIRONMENTAL EMERGENCY BASED ON INTERNET OF THINGS

At present, environmental monitoring just monitors a few of the key areas. It cannot detect the changes of environments accurately and response to environmental emergency timely. In this paper, Internet of things will be introduced to the monitoring of environmental emergency. Combined with the basic characteristics of the disposal of environmental emergency, the framework of environmental emergency disposal system will be constructed.

As shown in Figure 3, the disposal system of environmental emergency is mainly made of the perception layer, network layer and application layer. Its working principle is to install a variety of sensors and cameras sensing device, connect them through the
Internet, satellite and special environment network, transmit the data to the data processing platform, and use powerful processing function of the supercomputer technology, cloud computing to let huge data be processed and placed in the different servers of the data center. The monitoring department can get the data and implement early warning, decision making, treatment and rehabilitation of environmental emergency.

\subsection{Perception layer}

The perception layer is the most basic level of environmental emergency disposal system. It is equivalent to the human skin \& facial features and is used to collect environmental data. The technology of Internet of things is applied to environmental monitoring. Use the environment sensors, video cameras and radio frequency identification system to monitor soil, water, air, solid waste and noise in real time. That can collect the data of environmental quality, and strengthen the monitoring of pollution sources in order to obtain more complete data. Application of Internet of things can strengthen the monitoring efforts in the breadth \& depth, expand the scope of monitoring information, avoid information error \& distortion and enhance the existing capacity of environmental monitoring information system ${ }^{[3]}$. Simultaneously, it can also save human resources and improve the efficiency of collection. Now the problems to be solved are to reduce the power consumption, lower cost and miniaturization in the perception layer. Its trend of development is high sensitivity and overall perception ${ }^{[4]}$.

\subsection{Network layer}

The network layer is the intermediary layer of the disposal system of environmental emergency, which is equivalent to the nerve center of human body. Its main function is data transmission ${ }^{[5]}$. The network layer uses the wired network, the wireless network, proprietary network, satellite communication to transmit the data and integrates different technologies by CDMA, GPRS, 3G, WiFi, ADSL and other data transmission. At present, the uses of $3 \mathrm{G}, 4 \mathrm{G}$ make the transmission capacity of the network data improve greatly, which will facilitate application of Internet of things in the disposal of environmental emergency. The instantaneity and complexity of environmental emergency directly put forward higher requirements to the technology of the network layer. For example, to achieve the scenario of "An article an address, all online", the amounts of IPV4 address resources currently cannot meet the large terminal data, so we must upgrade IPV6 to provide enough data bearing ${ }^{[6]}$.

\subsection{Application layer}

The application layer is the top level of disposal system of environmental emergency and is the interface of Internet of things and the user. The application 
ICETA 2015

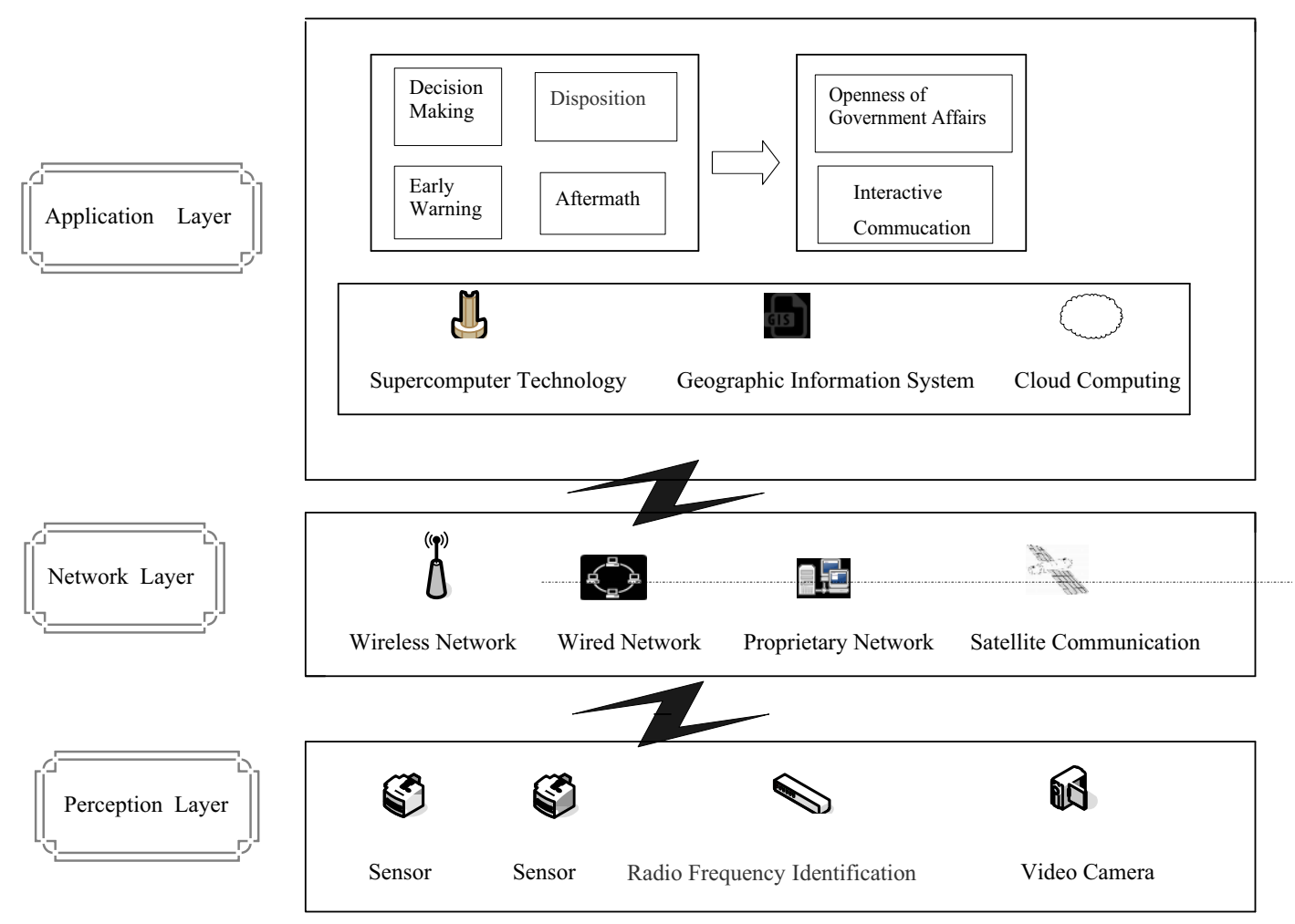

Figure 3. Diagram of the general framework of the disposal system of environmental emergency

layer is mainly responsible for the intelligent application of Internet of things, including the early warning, disposition and aftermath of environmental emergency [7].

In data processing platform of the application layer, we can use supercomputer technology, geographic information system, big data and cloud computing to manage and operate environment data. Through the data processing platform, we can deal with, store, and analyze the environmental monitoring data of the crossing region and industry, implement the storage of massive data timely, excavation and analysis of the models deep, the unified view of the real-time concentration of pollutants and the visual expression of pollutants of diffusion region. These are easy to grasp the development trend of pollutants and provide data support for a variety of application of the application layer.

On the basis of getting a large number of environmental monitoring data, the staff of monitoring center can analyze the tendency of environmental change through all kinds of models, warn the potential environmental pollution incidents timely and make the corresponding forecast. On the one hand, the warning information of environmental emergency is transmitted to the event location. After receiving the warning information, the governments at or above the level of county and relevant departments will take some measures. Launch the emergency plan immediately. Release the relevant prediction information and the results of evaluation to the public. Release the warning of unexpected environmental events hazard to the community. Propagate common sense of avoiding and reducing the harm to the publicity. Make the advisory telephone public. The production and business operation entity of occurring unexpected environmental events shall inform potentially contaminated harm to the related units and residents timely ${ }^{[8]}$.

When the early warning information of the monitoring system is confirmed and the event is verified for environmental emergency, the response of the system is started. According to different types of incidents, we can invoke the atmospheric pollution model and analyze the range \& extent of harm of the events to provide scientific and quantitative information support for decision making. Provide the treatment scheme \& process of the pollutant and emergency by using the bases of pre-arranged planning and knowledge ${ }^{[9]}$. At the scene of the accident, the command staff can be more intuitive to mobilize vehicles and personnel through the based map of GIS and the emergency detection car with GPRS. The staff at the scene implements on-site inspection to determine the types of pollutants, the ranges of contaminants, the degrees of pollution and transmit the results to the emergency command platform through the communications 


\section{MATEC Web of Conferences}

equipment of Pda and the intelligent mobile phone. These will provide accurate and reliable monitoring data for decision makers, and they are conducive for decision makers to develop the follow-up emergency work and also save the precious time ${ }^{[10]}$.

After the environmental emergency has been controlled effectively, we can analyze the accident, and determine the scheme of environmental pollution restoration. Then, we can analyze the process of the accident, determine the grade of the accident, archive the related accident information and provide the reference for dealing with similar accidents. Simultaneously, through this platform the people can obtain the information timely, such as the reasons for events happening, the measures taken by the government, and the transparency of the implementation of environmental emergency information, to enhance the credibility of the government, and reduce the possibility of the outbreak of mass environmental events ${ }^{[11]}$.

4 FACTORS OF RESTRICTING APPLICATION OF INTERNET OF THINGS IN THE DISPOSAL OF ENVIRONMNETAL EMERGENCY

In 1995, Internet of things was applied to dealing with environmental emergency in China. The standardized renovation of the sewage outfall was carried out in 60 cities of Jiangsu, Jilin, Shandong, Henan \& Anhui provinces. Since 2001, some local environmental protection departments have begun the construction of automatic monitoring system of key sources of pollution in this area and applied it to the management and law enforcement of environmental monitoring. In August 2011, the exercise of environmental emergency monitoring was held by the Ministry of Environmental Protection in China. Environmental emergency management system used Internet of things, "cloud computing", 3G, 3S and other means of information technology to support the environmental emergency work effectively ${ }^{[12]}$. In 2012, the Ministry of Industry and Information Technology announced "the Twelfth Five-Year Development Planning of Internet of Things", which pointed out the 8 key applications of Internet of things in China ${ }^{[13]}$. Intelligent environmental protection is one of them. Therefore, application of Internet of things in the disposal of environmental emergency is very broad, but the field is still in the initial stage. There are still some negative factors in technical level, technical standard, quality of personnel, information security and other aspects. These restrict application of Internet of things in the disposal of environmental emergency. These factors are the following.

\subsection{Lack of recognition}

Because of the complexity of the disposal of environmental emergency and the variety and huge amounts of information, these need to use Internet of things to improve the level and ability of management \& deci- sion-making to solve environmental emergency effectively. Internet of things is an emerging industry. Its application in the disposal of environmental emergency is a kind of new technology. At present, many local governments and environmental protection departments don't trust this new technology and is difficult to understand the roles of Internet of things in disposing environmental emergency comprehensively. This leads to that the enthusiasm of application of Internet of things in the disposal of environmental emergency is not high and the effect is not obvious. Therefore, the governments and environmental protection departments at all levels need understand the effect of Internet of things in the disposal of environmental emergency, and increase investment and strengthen management to solve the problems of environmental emergency effectively.

\subsection{Immature of the technology}

At present, the relevant technology is not mature and needs to be further improved. In the perception layer, the function of a variety of environmental sensors is single, so that the types of monitored pollutants are few and the reliability is not high ${ }^{[14]}$. A considerable part of them rely on imports and the price \& cost of maintenance are high. In the network layer, many mature advanced technologies of information \& communication are not applied sufficiently. The extent of being involved in the next generation network, cloud computing and other technologies is not high. In the application layer, due to lack of overall planning and top-level design, the amount of information is too large. This leads to the difficulty of information integration and cannot be applied comprehensively, so the actual effect is limited. In addition, there are some technical details to be further improved. For example, how to improve the reliability and effectiveness of data acquisition and transmission in bad weather conditions; how to provide energy for monitoring devices placed on the outside; how to provide environmental information to the crowd in remote areas or in outdoor work.

\subsection{Lack of unified technical standards}

At present, the field covered by the technology of Internet of things is very wide. The relevant enterprises occupy the dominant position in their familiar domains and claim their systems. There is lack of unified technical standards. Take FRID technology as an example, in 2006 China established the standard of wireless sensor network group, but now it has not a unified standard. Our country has only developed six national standards of the sensor network on general provisions, terminology, interface, security, identification, and network. More than 10 standards are not unified ${ }^{[15]}$. The main participants of constructing environmental emergency system are all levels of local governments. The local governments and the related development companies usually customize the dispos- 
ICETA 2015

al system of environmental emergency. However, influenced by the environment of Internet of things and the local interests these customization projects are often lacking of replication. There are no standard communication interfaces among the disposal systems of environmental emergency in different areas. It makes that environmental information resources cannot be shared. If appropriate technical standards are not developed as soon as possible, all levels of governments will be fragmented, which is bound to affect the disposal of environmental emergency. That is also not conducive to the integration of environmental emergency disposal system.

\subsection{Safety problems}

The disposal system of environmental emergency is a multi-network integration of heterogeneous networks [16]. In this system, the issues of information security, network security and even national security become more prominent. It will make security protection system and the cognition of the existing security system face the severe challenges. Compared with the traditional network, the disposal system of environmental emergency has its particularity, such as the problems of data security, privacy protection, the authentication of heterogeneous network, access control, information storage and management.

\subsection{Structure of technical personnel}

Due to the special property of the work of environment, it is required that the practitioners must have a high level of technology and good practical ability. However, because of poor working conditions, unfair treatment and low pay, few people voluntarily choose to engage in this work in China. At present, the quality of technical personnel engaging in environmental monitoring is not high. The proportion of talents of higher degree, such as professors and engineers, is still relatively small. The personnel engaging in the industry are ordinary workers. The cultural level of them is not mostly high, which restricts the development of environmental monitoring technology and emergency disposal in a certain degree.

\section{COUNTERMEASURES AND SUGGESTIONS TO OPTIMIZE ENVIRONMENTAL EMER- GENCY DISPOSAL SYSTEM}

\subsection{Improving technology}

With application and popularization of Internet of things in the disposal of environmental emergency, some problems gradually emerge. This proposes higher technical requirements to Internet of things.

\subsubsection{Technology improvement of the perception layer}

As an important means of the perception layer getting environmental information, the sensor should have the ability to perceive the heat, light, sound, electricity, power, and other signals accurately. It can provide the most original information for the processing, transmission, analysis and feedback of the network layer. Simultaneously, as the special application for Internet of things in the disposal of environmental emergency, the sensor should meet the requirement of large-scale installation in unattended environment and adapt a variety of harsh application environments. Therefore, the traditional sensor gradually should be the miniaturization, low cost, low power consumption, intelligence, informatization, and networking. It will experience the development process from the traditional sensor, the intelligent sensor to the embedded web sensor. New materials, MEMS (Micro-Electro-Mechanical-Systems), miniaturization sensor, intelligent information storage sensor and multifunctional sensor will become a hot issue of research in the future. Research on RFID technology in the future will focus on the research of anti-collision, RFID antenna, the choice of operating frequency and the security \& privacy ${ }^{[17]}$. In general, we can develop the technology of sensor to solve the problems that the acquisition method of the perception layer information is few, the acquisition way is backward and the updating is not timely.

\subsubsection{Technology improvement of the network layer} In the network layer, it can improve the technology from the following points. First, accelerate the application of new technology. Use the latest achievements of digital technology and network technology of a new generation, such as $3 \mathrm{G}$ network, and LTE wireless access technology. The application of new technology can ensure the quality of data transmission and further promote the application of Internet of things in the disposal of environmental emergency. Second, improve and optimize the network access layer and network. According to the characteristics of telecom network to environmental emergency, the technology of wireless access, the short distance communication, heterogeneous network are optimized. Third, establish multi network platform. At present, Internet of things mainly relies on the telecom network to operate. If this single network platform faces the complex changes in the natural environment, the telecommunication network will be destroyed and Internet of things will stagnate ${ }^{[18]}$. Because the telecommunication network is an open network, Internet of things needs to face all kinds of network security risk. Therefore, in order to ensure the normal operation of environmental protection work, multi network platform needs to be established. 


\section{MATEC Web of Conferences}

\subsubsection{Technology improvement of the application layer}

Focus on strengthening the capability of data processing in the application layer of Internet of things. All the time, the application layer will receive a large number of environmental data from the perception layer. Some data have great contributions to the decision, but some data have smaller help. The processing of massive data needs to have the super computing power to find useful decision information and process intelligently. In addition, we need break the barriers of information between all levels of government and the environmental protection agency to share a variety of environmental resources. In this way, it can reduce the inaccuracy of the judge of the single sector, so that the various departments at all levels of leadership can grasp the information comprehensively, accurately, and timely at the first time and develop risk assessment and treatment of emergency.

\subsection{Strengthening management}

Application of Internet of things in the disposal of environmental emergency is the inevitable trend of information technology in the field of environmental protection. At present, Chinese Internet of things industry is still in the formation period. The sectors of industry and technology are in relatively chaotic stage. This requires the government to define the development direction of Internet of things, key research areas, technical standards and norms clearly. Application of Internet of things in the disposal of environmental emergency should be arranged unifiedly.

\subsubsection{Scientific planning and top-level design}

At present, application of Internet of things in the disposal of environmental emergency is still in the early stage. The government should do the top-level design \& unified planning, clear strategic positioning of development, formulate the long-term development program of application of Internet of things in environmental emergency to promote the application step by step. Recommend to establish an inter departmental leadership team, guide unifiedly, coordinate and deal with all aspects of the problems, balance the conflicts of interest of various departments and form the resultant force in the development ${ }^{[19]}$.

\subsubsection{Establishment and improvement of relevant} policies, laws and regulations

Application of Internet of things in environmental emergency is not only the technical problems. The process of construction of Internet of things involves the problems of planning, management, coordination, cooperation and the protection of personal privacy. To maintain the healthy development of Internet of things, it needs to establish and perfect the relevant policies, laws and regulations. For example, the problems of the legitimacy of information collection, privacy of citizen right, network security are required to formulate a new "rules of the game" ${ }^{[20]}$.

\subsubsection{Paying more attention to the setting process of} the standards of Internet of things

Setting the standards of Internet of things is a process of continuous improvement and will continue for a long time. Many countries have researched the relevant technology of Internet of things actively, but no unified standard system has been formulated. The formulation of standard system as soon as possible becomes one of the key factors for the development of Internet of things ${ }^{[21]}$. The level of some technologies of Internet of things in China has ranked in the world and our country is an international leader in some aspects, so our country can become the dominant country of standards in the setting process of international standards. In the field of basic standard, China can participate in the formulation of international standards. Simultaneously, we should be combined with our own situation, accelerate the setting of the related standards of Internet of things, adhere to international \& national standards to strive for our right of speaking in the field of Internet of things and enhance the international competitiveness of our country in the field of Internet of things.

\subsubsection{Increasing investment}

Disposal of environmental emergency is beneficial for the nation and people. Increase the national special funds on the disposal of environmental emergency. The funds of application of Internet of things in the disposal of environmental emergency should be included in the government budget of capital construction. Actively guide the local government to increase the fund investments. Simultaneously, the special funds are established for the research and construction of environmental emergency disposal system to ensure scientific research and realize environmental emergency disposal intelligent.

\section{CONCLUSION}

The disposal of environmental emergency is a complicated system, which is based on the complete data storage and in-depth research. The disposal system of environmental emergencies is the use of Internet of things to strengthen the collection, transmission and integration of the various environmental monitoring data. It can achieve early warning, trend prediction, event handling of environmental emergency. The establishment of environmental emergency disposal system is bound to promote the construction of the environmental emergency response capabilities, improve the level of environmental decision-making, secure the safety of people's lives and property effectively and promote the development of social stability. But because there are the restrictions of technical level, technical standards, quality of personnel, security issues and other restrictions, the popularization and application speed of environmental emergency disposal system are subject to certain constraints. In order to solve these problems, we should further improve 


\section{ICETA 2015}

the technology, and strengthen management in order to build an environmental emergency full coverage, operation, application and sustainable management system.

\section{REFERENCES}

[1] The National Environment Statistics Bulletin, www.mep. gov.cn/zwgk/hjtj.

[2] Liu Jin \& Gu Jiaqiang. 2013. The current situation and development strategy of internet of things in China, Enterprise Economy, (6): 4.

[3] Jia Yigang. 2010. Application of Internet of Things in environmental monitoring and early warning, Shanghai Construction Science and Technology, (6): 66.

[4] Xiao Qing. 2012. Introduction to standard system of Internet of things, Technology and Standardization of Telecommunication Engineering, (6): 10.

[5] Wu Danna, Jiang Hong, Zhang Jinmeng, Chen Yunfei, Yuan Jian. 2014. Application of Internet of things technology in environmental monitoring, Anhui Agricultural Science, (10): 3077.

[6] Li Hongtao, Ceng Yuanshan, Wang Yangyang. 2012. Research on application of Internet of things in environmental protection industry, China Environmental Protection Industry, (6): 28.

[7] Cui Man, Xue Huifeng, Bu Fanbiao, Zhao Xiaoping. 2013. Research on environmental monitoring system based on Internet of things and cloud computing, Journal of Xi'an Technological University, (7): 580.

[8] Early warning of environmental emergency can be divided into four grades, http:// news. sina.com. cn/o/2013-01-27/ 062026132652.shtml.

[9] Yi Wenjie Ou Zhonghao Luolin, 2013. Research on the structure and function of Hunan environmental emergency command system, Hunan Water Conservancy and Hydropower, (5): 66.

[10]Yang Hao, Xiao Wei, Xie Xuejun, Huang Lei. 2011. Based on the geographic information technology the design and development of environmental protection and emergency system, Gansu Science and Technology, (12): 22.

[11] Yang Hao, Xiao Wei, Xie Xuejun, Huang Lei. 2011. The design and development of environmental protection and emergency system based on the geographic information technology, Gansu Science and Technology, (12): 22

[12]Zhang Shuli, Hao Jun, Zhang Wei. 2012. Study on application of IOT in environmental protection of technology, Chinese Environmental Management, (4): 27.

[13] Notice of 12th Five-Year Development Plan of Internet of things, http://kjs.miit.gov.cn/n112934 72/n11295040/n11478867/14344522.html.

[14] Tan Li, Xia Luohui. 2011. Internet of things boosting the informatization of the environmental monitoring, Telecom World, (11): 72.

[15]Xie Xiaoyan. 2012. Analysis of the characteristics of the development of Internet of things. Enterprise Economy, (9): 101.

[16]Zhu Hongbo, Yang Longxiang, Zhu Qi. 2011. Development and application of the technology of Internet of things, Journal of Nanjing University of Posts and Tele communications (Natural Science Edition), (2): 4.

[17] Tian Tiehong, Cheng Geng, Mao Song, Tan Hu. 2010. The development of Internet of things orienting environmental protection, Information and Communication Technology, (5): 33.

[18] Yang Aimin, Li Haibo, Lv Yuxin. 2013. Intelligent environmental protection making the environment more beautiful, Heilongjiang Environmental Bulletin, (3): 2.

[19]Xiong Sanlu. 2011. The countermeasures and suggestions of the development of Chinese Internet of thing, Science and Technology Management Research, (4): 167.

[20]Cui Ruiqin, Wang Zigang, Lin Fang. 2013. Study on the development and related problems of Internet of things in China, China Information Times, (4): 69.

[21]Shen Hongliang. 2013. Study on the problems and countermeasures of the development of Chinese Internet of things, Master Thesis of Capital University of Economics and Business, 39. 